\title{
Toward a Comprehensive Performance Measurement System
}

Eltemsahi, Ayman PhD

Arab Academy For Science and Technology

College of Management and Technology

Business Administration Dept.

P.O. Box 1029, AASTMT, Miami 
Toward a Comprehensive Performance Measurement System

\author{
Fltemsahi, Ayman PhD \\ Arab Academy For Science and Iechnology \\ College of Management and Technology \\ Business Admumstration Dept \\ P.O. Box 1029, AASIMI, Mamı \\ Alexandria, EGYPT \\ Tel: $\quad+2-03-5485473$ \\ Fax: $\quad+2-03-5566072$ \\ E-mail: eltemsahi@yahoo.com
}

\title{
Abstract:
}

Many scholars in the recent years have given great attention to the importance of strategic measurement systems including both financial and non-financial measures. The purpose of implementing a comprehensive performance measurement system is to improve strategic management of an organisation. Decision makers should get feedbacks on how the organization is performing on strategic goals. The Balanced Scorecard (BSC). was introduced by Kaplan and Norton as a strategic performance measurement system, using objectives and measures across four perspectives taken from an organization's vision and strategy. The emergence of the balanced scorecard in the 90's attracted the attention of both practitioners and academics. They were hoping to reach a complete strategic measurement system. It is, therefore, worth asking whether this is a valid model for obtaining the results promised. In this paper the concept of the balanced scorecard is discussed in detail. Then, a critique of implementing the balanced scorecard is discussed. Also, system dynamics as a supportive tool to overcome the limitations of the BSC is presented.

Key Words: Performance measures, Balanced Scotecard, Financial measures, Non-financial measures; system Dynamics

\section{Introduction:}

Most firms in today's environment are adopting new manufacturing technologies and quality philosophies such as just-in-time (JIT), total quality management (TQM), and computer integrated manufacturing (CIM). The Traditional Cost Accounting System (TCA), which developed over the past fifty years, and focused on determining the cost of goods sold and inventory value does not fulfil today's management needs nor matches the new operating philosophies (Sieger, 1997, Atkinson, 1997, Brimson 1991. pp. 7-10, Johnson, 1991). Traditional cost accounting measures have been criticized for their inadequacy in providing performance indicators that can clearly help a company achieve its ultimate goal. The measures are known to sometimes produce conflicting and misleading information that could undermine the achievement of a company's strategic objectives. 


\section{Traditional Financial Measures} don't consider the nature of the business encen when a new manuacturing technology as an automated production line is introduced, the majority of the cost will be fixed ca this means that performance reports which compare actual costs with standard costs be of little help in improving an organization's performance. For example, firms that . adopting Just in Time (JIT) techniques and still relay on traditional performas, measurement, would mostly produce irrelevant feedback for the workers to use improve their performances. Although some financial measures are still needed reporting and certain improvement purposes, there are obviously many that should eliminated. These measures include direct labor efficiency, labor and machine utilization labor productivity, and labor and overhead variances. These measures emphasiz performance to a standard and encourage over-production. For example, utilization is measure used as a means to maximize output from any one machine or one worker. This type of measurement contradicts the JIT principle that requires small batches, leve production, pull not push system, and producing only what is immediately needed, no more and no less (Azmi; Satish; Pletcher, 2002).

Financial measures were also criticized because these measures are based on past actions rather than future development. For example, the ROI can be computed only after profits have been totalled for a given period, i.e. ROI tells us what has happened not what is happening or going to happen. This means that it comes too late to be of value Moreover, the traditional financial reports are not able to measure improvement in arear like innovation, learning, and lead-time (Waitzer, 1997). Management needs to have early warning indicators of future problems before crises happen. Also, management needs measures that can signal future opportunities (Schiemann and Lingle, 1997).

\section{Non-Financial Measures} Firms have tried to overcome perceived limitations in traditional accounting-base
performance measures by using non-financial measures for decision-making an
performance evaluation. Non- financial performan performance evaluation. Non- financial performance measures are tools that are used measure non-financial results (non-quantifiable data) such as customer satisfactiol performance; therefore it may betc. They serve as indicators for a firm's long-ten Moers, MARC working paper, March 20d in incentive contracts (Kaplan, 2001; Frar if the available financial performan 2000; Hoffman, 2001). They are usually releva contribution to the firm's total value. One reason suggested for the use of

leading indicators future firm's of non-financial measures that they are considered accounting measures in rewardinformance and thus provide information incremental Lipe and Salterio,2000). For rewarding and motivating managers (Kaplan and Norton 199 improve the quality level in their firms, measuring quality will encourage managers satisfaction, which may lead to increasich lead to increase the level of custom 
reducing the lead time will reduce the inventory level, reducing the inventory level frees up working capital which would reduce debt, this debt reduction will lead to reduction in cost resulting form reducing interest, finaliy this will lead to improved earnings.

Empirical studies by Ittner and larcker (Customer satisfaction, future accounting performance, 1998), and Banker et al. (Customer satisfaction-future accounting earnings, 2000) supports the role of non-financial measures as leading indicators of future financial results. Such leading indicators are necessary for performance measurement and management compensation when current managerial actions influence the firm's long term financial results, but are not reflected in current accounting measures (Hoffman, 2001; Christian Hoffman, University of Hanover, September 2001; Ittner and Larcker, 1998; Waymond Rodgers et al., September 2001).

Non-financial measures were also criticized as having no balance between the nonfinancial measures and strategic objectives. If the aim of the measurement is not aligned with the strategic objective of the organization, the evaluation process will be a failure. Thus efforts were made to include non-financial measures linked to strategy (Kaplan and Norton, 1992; Ittner et al, 1998).

\section{The Balanced Scorecard}

The concept of the balanced scorecard was introduced to complement financial measures with those related to: customers; internal business process; and learning prospective. The validity of the BSC relies on the assumption that the cause and effect relationship exists between the areas of measurement suggested. The balanced scorecard was then introduced by Kaplan and Norton in 1992 as a model that balances the financial and non financial performance measures. The financial measures reflect the past performance while non financial measures are the drivers of the future performance, so the problem of the historical nature of accounting data is solved. The concept of the balanced Scorecard (BSC) was first introduced by Robert S. Kaplan and David P. Norton in 1992. In the past ten years, many firms and applied the BSC. For example, Kaplan and Norton (2001) reported that by 2001 about $50 \%$ of the fortune 1000 companies in the North America and $40 \%$ to $45 \%$ of the companies in Europe were using the BSC.

Kaplan and Norton define the Balanced Scorecard (BSC) is "a set of measures that give top managers a fast but comprehensive view of the business". It includes financial measures of the results of actions already taken. It complements them with operational measures on customer satisfaction, internal processes, and the organisation's innovation and improvement activities-operational measures that are the drivers of future financial performance" (Kaplan and Norton, 1992).

These four perspectives are linked to the company's vision and strategy to provide the framework for the balanced scorecard as shown in figure one. 
How do we generate value for

our shareholders?

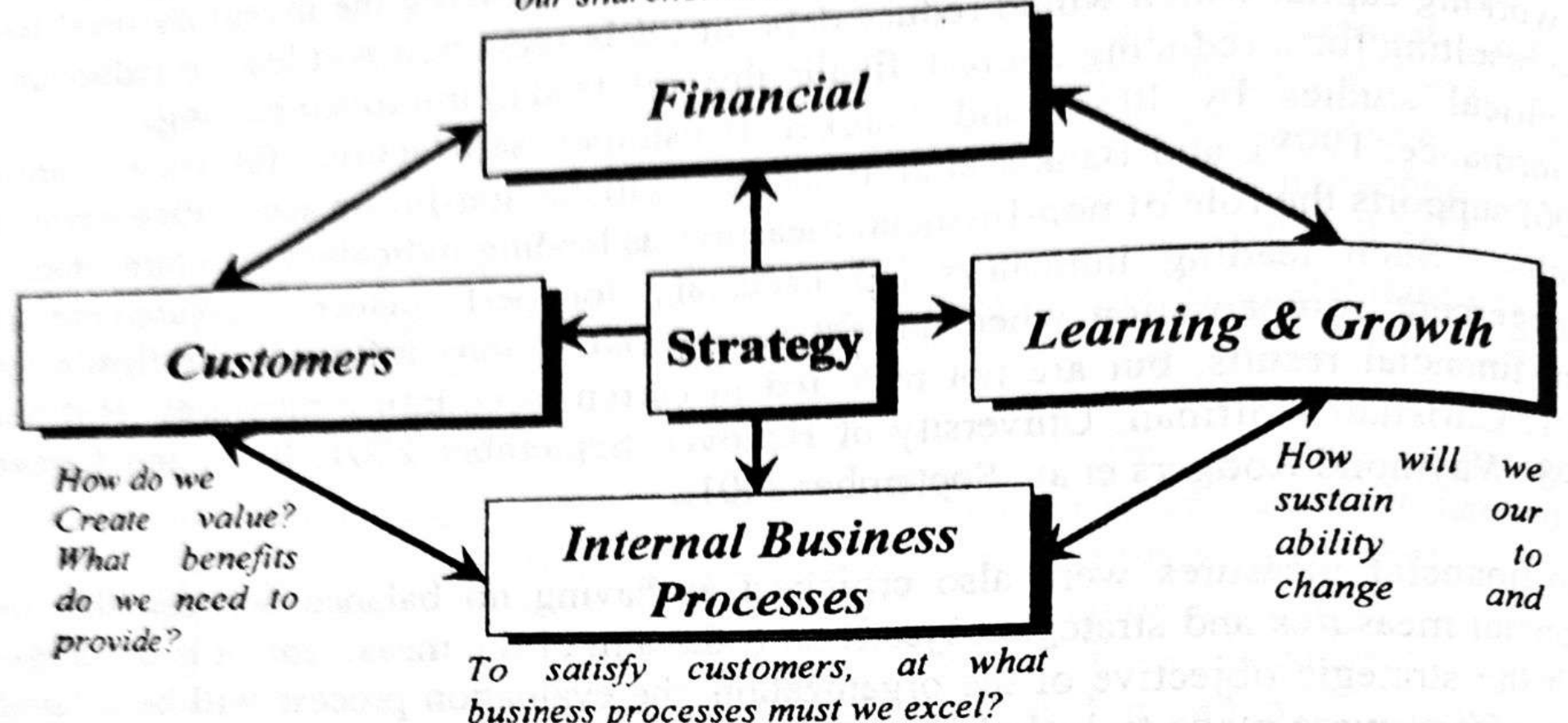

Figure one: Basic Design of a Balanced Scorecard Performance System

Source: Robert S. Kaplan and David P. Norton, "using the Balanced Scorecard as a Strategic Management System," Harvard Business Review (January-February 1996)

The BSC approach as shown at figure one consider a holistic thinking by recognising the existence and the importance if the operational aspects of business and the idea of future potential (Wolstrnholme, 1998). The design of the four perspectives that in turn, driven from an organization vision and objectives allows mangers to broaden out there performance measurement to include measures other than financial. Building a performance measurement system across the organization is an important step in developing a system perspective.

The basic premise of the BSC is that financial results alone cannot capture value creating activities (Kaplan \& Norton, 2001). In other words, financial measures are lagging indicators and, as such, are not effective in identifying the drivers or activities that affect financial results. Therefore, Kaplan and Norton (1992) suggested that firms, while using financial measures, should develop a comprehensive set of additional measures to use as leading indicators, or predictors of financial performance. They suggested that measures
should be developed that address four perspectives.

A balanced scorecard for a certain business unit should explain the relationships between outcome measures and the performance drivers of those outcomes, which explain how
the outcomes are to be achieved. Also, it helps managers minimise the information and
focus on few measures, instead of following irrelain the relationships between focus on few measures, instead of following irrelevant information. Therefore, firms that 1992; Lawrie, G.J. and Cobbold, I. 2004). 


\section{Benefits of Implementing a Balanced Scorecard}

Balanced Scorccard is a potentiaily powerfui tooi that heips managers to trac hisation performance. It focuses on establishing links between strategic objective: nd performance measures. The balance scorecard approach is also concerned about the elationships of other stakeholders such as employees, customers, government, anc uppliers. Applying a successful BSC across the organisation would create a strong organised communication system between top management and floor management. also addresses the importance of intangible assets of a firm such as intellectual capital nd competency. The major strength of this approach is the combination of financial and non-financial indicators and how these measures are linked to an organisation strategy.

Meanwhile, regular reports and meetings with operation managers help top management explain or clarify what is behind the numbers, which are shown in reports. These kinds of meetings allow management to evaluate the current and future potential investment. Throughout the BSC a company's performance can be presented in an organised and comprehensive document, instead of several different documents which have a lot of nformation that requires enormous time and effort for analysis. The way of viewing or oresenting the four perspectives at the BSC provides good opportunities formanagement to learn and study the key success factors and the weakness inside and outside their organisation for continuous improvement (Kaplan, R.S., \& Norton, D.P. 2004).

\section{Limitation of Implementing the Balanced Scorecard}

Kaplan and Norton, 1996, define the relationships between the four main areas using ause and effect relationships. They demonstrate these relationships by using and xploring the effect of the four areas on each other. As an example, learning and growth re therefore the drivers of the measures of the internal business process. The measures f these processes are in turn the drivers of the measures of the customer perspective, vhile these measures are the drivers of the financial measures. It suggests causal loops ut one problem is that the authors do not close the loop. They recognise the causality ut do not introduce the concept of feedback. Although this chain theoretically makes ense, however it is a simplification of reality (Otley, 1999).

he authors' emphases that each strategic area should have both lead and lag indicators, ielding two directional cause and effect chains. These indicators apply horizontally ithin the areas and vertically between areas. The causal paths from the measures adicators on the scorecard should be linked to financial objectives. However, in real life he impact of some decisions would be recognized in short term but others need longer me. This is due to a time lag between cause and effect. The effect of the measures ccurs at different points of time because the effects of different areas involve different me scales. For example, reaching customers satisfaction as a result of corrective actions ould be reached in few months while innovation may not affect the financial results intil few years have passed. Also, there are many factors affect the accounting results. 
Thus, it might be difficult to determine when the financial effect of an action will
or what impact of the effect will be. According to Kaplan and Norton, 1996, pp.224-249, the strategic objectives have to $b_{e}$
broken into budgetary targets to be reached over time. In the short-term, managers set
target that will yield a target profit. Managers use a budget that shows a time path
product volumes, prices, and cost. As time goes by, managers test their perform product volumes, prices, and cost. As time goes by, managers test their performance by comparing the actual results with the targets and check out any variances. Correctiv actions are taken to bring the behaviour into line. However, it is still a static sective
which does not solve the time lag problem

According to (Otley, 1999, pp.374-375), the BSC is a comprehensive performance measurement system that includes financial outcome and short term measures as well as non financial driver and long term measures. Therefore, firms that adopt the BSC were Also, these firms are expected to reduce the likelihood of previously observed disagreement and conflict between top management and divisional mangers by promoting a more holistic approach to performance evaluation. However, the finding of recent field studies, mentioned later, suggest that the unique features of the BSC is not sufficient to overcome performance evaluation bias that can result in disagreement and conflic between top management and divisional managers.

Some of these recent filed studies revealed that in one hand, the implementation of the $\mathrm{BSC}$ is not that easy task. On the other hand, as a result of selecting common measure rather than a particular key performance indicators (KPI), it might provide wron information about the performance of divisional mangers for top management (Lipe an Salterio, 2000 and Lipe and Salterio, 2002; lttner et al., 2003 and Malina and Selto 2001). For example, Lipe and Salterio (2000) found that the supervisions' evaluation 0 divisional managers' performance using BSC was based only on common measure across different business units, and not on the measures that were unique to particula various de-biasing techniques, such as providing evaluators with strategy map (Banke Chang, \& Pizzini, 2004), disaggregating the BSC measures (Roberts, Albright, of BSC measures (Libby, Salterio, \& Webb, 2004).

Another study by (Ittner and Larcker, 2003 and Ittner et al., 2003b) on manufacturing an service companies that adopt the BSC suggest that the causal links between drivers an outcome measures are often overlooked. This study showed that among those firms th create causal models, only $21 \%$ go on to validate the causal links between driver an outcome measures. They also observe "businesses often fail to establish such links part out of laziness or thoughtlessness" (p. 89). The results from this study indicate that th information about strategy effectiveness is available in the BSC, but it is not used much as would have been expected presumably due to inadequately implementation an
because of cognitive limitations. 

tendency to overlook the validity of the casual links between driver and outcome measures of the BSC is a potential source of conflict between top management and divisional managers.

From the previous discussions one can concludes that the problem is not of the adaptation of the BSC concept, however, many reasons are impacting the final results. Poor implementation of the BSC concept and mangers' perceptions towards the selected performance measures that reflect the performance of divisional mangers are good examples.

Although, Kaplan and Norton explain how to select specific performance measures for each of the four areas, the selection of these measures is not easy. Some of them are final outcomes such as customer satisfaction. Others such as delivery time or product quality have to be carefully defined in ways that allow a management to trace how those results are to be achieved. Therefore, there is a need for another supportive tool to enhance the effectiveness of the BSC and overcome the wcakness that showed during the implementation stage. System dynamics is the selected tool that would work well with the BSC. By building a causal loop, managers can recognise the causal links of non financial measures on the performance and on the financial measures outcomes. According to Kaplan and Norton (1996, p. 85)," if the unit's employees and managers have delivered on the performance drivers, then their failure to achieve the expected outcomes signals that the theory underlying the strategy may not be valid".

Although, the BSC is considered a comprehensive strategic plan for any given organisation that produces products or provides services (Kaplan and Norton, 1996), it is essentially a static representation of complex dynamic systems. It fails to cope with dynamic business requirements. Thus the aim of this paper is to suggest a dynamic concept that would work well and enhance the validity "of the BSC. This is an area, which is explored in this paper.

\section{System Thinking}

System thinking was developed in the late fifties as a method to deal with problems in complex systems. The essential properties of a complex system are derived from its internal relationship. In technical terms system thinking is; understanding relationships and patterns between components in a network of relationships. Holistic perspective is also known as "systemic" and the way of thinking it involves "system thinking" (Senge, 1994). Holistic thinking means that the whole system under investigation is being considered as one unit, a human body is a good example. Thus a good physician must consider the impact of a certain medicine on the rest of the body when he or she treats a certain disease to avoid creating other problems. In management field solving a problem without considering the interdependencies of all the parts of an organization might lead to create another one. 
By shifting the attention towards interdisciplinary approach, system thinking plays a vita] role in problems analyses. It enables one to understand causes and effects of problem and
how different aspects of society and the natural environment interrelate through feedbaci loops (Sterman, 2000). In general terms system thinking is mental modelling and science of structuring logic but it has also a practical application called system dynamics which was developed in the sixties by Jay Forester at MIT. System dynamics deals with mathematical representation of our mental models and is a secondary step after we have developed our mental model

\subsection{System Dynamics}

System dynamics is an approach for studying the world around us through modelling and simulating dynamical systems. It is a method to enhance learning about complex systems (Sterman, 2000). It considers a framework for thinking about how the operating policies of a company, its customers, competitors, and suppliers interact to shape the company" performance over time (Forrester, 1961). Simulation models are helpful in learning about dynamic complexity, understanding the sources of policy resistance, and designing more effective policies.

Forrester introduced system dynamics at the early 1960's at the Massachusetts Institute of Technology (MIT). He defined system dynamics as "the investigation of the information-feedback characteristics of [managed] systems and the use of models for the design of improved organisational form and guiding policy" (Coyle, 1996). System dynamics emphasises dynamic relationships at the expense of static ones and relies heavily on the feedback concept and using a causal loop diagrams.

\subsection{The Causal Loop Diagram}

In System Dynamics, one first tries to identify causes and effects by using causal loop diagrams. These are considered a vital tool for representing the feedback structure of system and are considered a core concept of System Dynamics. A casual loop diagram consists of variables connected by arrows to show causal influences. Only two types of relationships exists either positive or negative loops:

In positive feedback loops, an increase in a variable leads to further increase in the same variable. Therefore, positive feedback is usually called a reinforcing or amplifying process thus causing exponential behaviour. For example, as bank account balance increase, interest would increase, all other things being equal. On the other hand, negative feedback loop, an increase in one variable leads to a decrease in the sam variable. For example, as number of complaints increase, customer satisfaction decrease all other things being equal. Negative feedback reflects equilibrium or the stabilisation of a system (Georg, 2005). In management systems, a closed loop is required and essential for intrinsic control. An absence of a closed loop indicates either the diagram wrong or the system has no intrinsic control (Forrester, 1961).

The interaction of positive and negative feedback loops is the reason of the dynamic behaviour. By using causal diagrams, one can understand the basic structure of a system 
and how all the objects in a system interact with each other. A system dynamics model sims to simulate these diagrams using predetermined relationships between the linked ariables. By applying different scenarios, it can describe the behaviour of the system in different situations to help management reach appropriate decisions.

Today the system dynamics method has an established role in the description and understanding of complex dynamical systems. System Dynamics is currently used in a wide variety of both academic and practical fields as an effective analytical tool. Firms such as AT\&T, BT, Ford, IBM, Fortune 500, and others are using system dynamics to improve the quality of decision-making and planning (Sterman, 2000, Santos, 2002; Senge, 1994).

\subsection{System Dynamics Components}

System dynamics builds on information feedback theory that provides symbols for mapping business systems in terms of diagrams and equations. The theory of system dynamics is based on the relationships between stocks and flows. A variable is categorised as a stock, flow or constant. Stocks can be defined as quantities or accumulations of material. They can represent tangible quantities such as, money, people, and materials as well as intangible variable such as, perceptions and expectations (Sterman, 2000; Santos, 2002).

Flows are the rates that lead to changes in the stocks or levels. It is important to know that items added to a stock remain constant until other addition transactions (inflow) or till other withdrawals (outflows) take place. Thus, when an item flows from one stock to another, the second one will increase exactly by the same amount that the first one decreases. Therefore, in a given system only inflows and outflows can change the level of stock. For example, consider a bank account as stock, the money deposit into this account would be considered an inflow to the stock and withdraw of money considered an outflow. So, the level of this bank account is determined by two main factors, which are, deposit (inflows) and withdraws (outflows). Another example is the finished goods inventory. The level of finished good (stock) depends on the inflow of production and is reduced by the outflow of shipments.

The stocks in a given system describe the current situation and provide valuable information for decision-makers. Stocks can also be considered as a source of delays, which can be calculated by accumulating the difference between the inflow and outflow at a certain process. Also they could explain the reason for unequilibrium between the inflow and out flow in a dynamic system. It is important to match the units of measure of stock and flow in the same units per time period. If the balance sheet items (stocks) are measured in dollars then, the income statement items (flow) must be measured in dollars
as well.

\section{Integrated System Dynamics with the Balanced Scorecard} Based on the previous discussion, it is obvious that the BSC is an effective approach that
can translate the strategy into action (Kaplan \& Norton, 1996c). It also supplements the 

additional pers also used as a system for communication, the financial results $w_{\text {ing }}$ growth. It is alsolps the companies to track and evaluapabilities and acquirin while Consequently, it monitoring progress in building the capabilities and acquiring the simultaneously mon would need for future growth. Therefore, it's worth mentioning that intangible assets theplacement for financial measures; it is their complement (Kaplan \& implementing strategy.

On the other hand, looking at any organisation as groups of feedback loops is a very effective way for decision-makers. For example, the normal cash flow cycle starts from the cash flows generated by regular sales in one period, to purchase what it needs for the activities in the next period. These activities then create the sales that generate the required cash flow for future value adding activities. So, it is apparent that cash is moving in a loop over time with inflows being fed back into outflows that in tum generate new inflows. The same idea applies to output. Inventory levels at a previous period determine the output level for the next. If the inventory level for a previous period went up, the output for the current period would go down. The same idea applies to profit. - The higher the profit earned from a previous period, the more money would be added to working capital, and the more products offered to the market place and the higher the profit the company would get. Therefore, profit will be fed back into loops to determine the quantity of product to be made in the next period. Thus, there is seems to be a direct proportional relationship between the profits in previous period and the profits in the next one. Then, monitoring a business performance is simply moving around a large number of interrelated sales, output, cash flow, and profit feedback loops. Therefore, the performance indicators of a business are generated by feedback loops. At the same time, each of these loops depends on other loops, and each period affects the next one.

Using System dynamics along with BSC enable it to be a powerful tool to make sure that the right analytics are measured, monitored and acted upon. Therefore, using system dynamics to support the BSC would overcome some of its weakness such as static nature and time lag. System dynamics would enhance the power of BSC approach for seeking the root causes of a certain problem (Groesbeck et al., 2002). A mentioned earlier, a good BSC should have a mix of outcome measures (lagging indicators) and performance drivers (leading indicators) of the business unit's strategy. Outcomes (such as: cycle time and part-per-million defect rates) enable the business unit to achieve short these measures failed to reveal whether the recent filed studies revealed that translated into expanded business with existine operational improvements have been enhanced financial performass with existing and new customers, and eventually, into complement each other to explain how th, both outcomes and performance drivers 

interconnection relationships become easiersal loop. By using a causal loop the whole variable under investigations in to understand specially when putting the appeared at the causal loop by using sheet. Also, the expectation of delay is understanding of the interactions between marked arrows that would help for more satisfaction and total costs are affected by mand lag indicators. For example, customer other is lagging indicators. Thus, the impact indicators, some of them are leading and one area while takes longer time on other of certain decision would reflected soon on recognises the spending on training as just area. For example, the accounting system measured period. However, after a delay of tims which increases the total costs of the results of the training. Then deflect rate would decreamployees skills would improve as satisfaction. Meanwhile, adopting a policy of reducing which would increase customer advertising and promotion would increase sales and ining prices and spending more on Increase total costs as results of improveme total costs in the same time. quality; etc.) would reduce the profit in at other area (training expenses; improve learning and growth in short term. In a long term. This would affect the budget of negatively impacted then customer satisfaction would decrease which would reduce the sales.

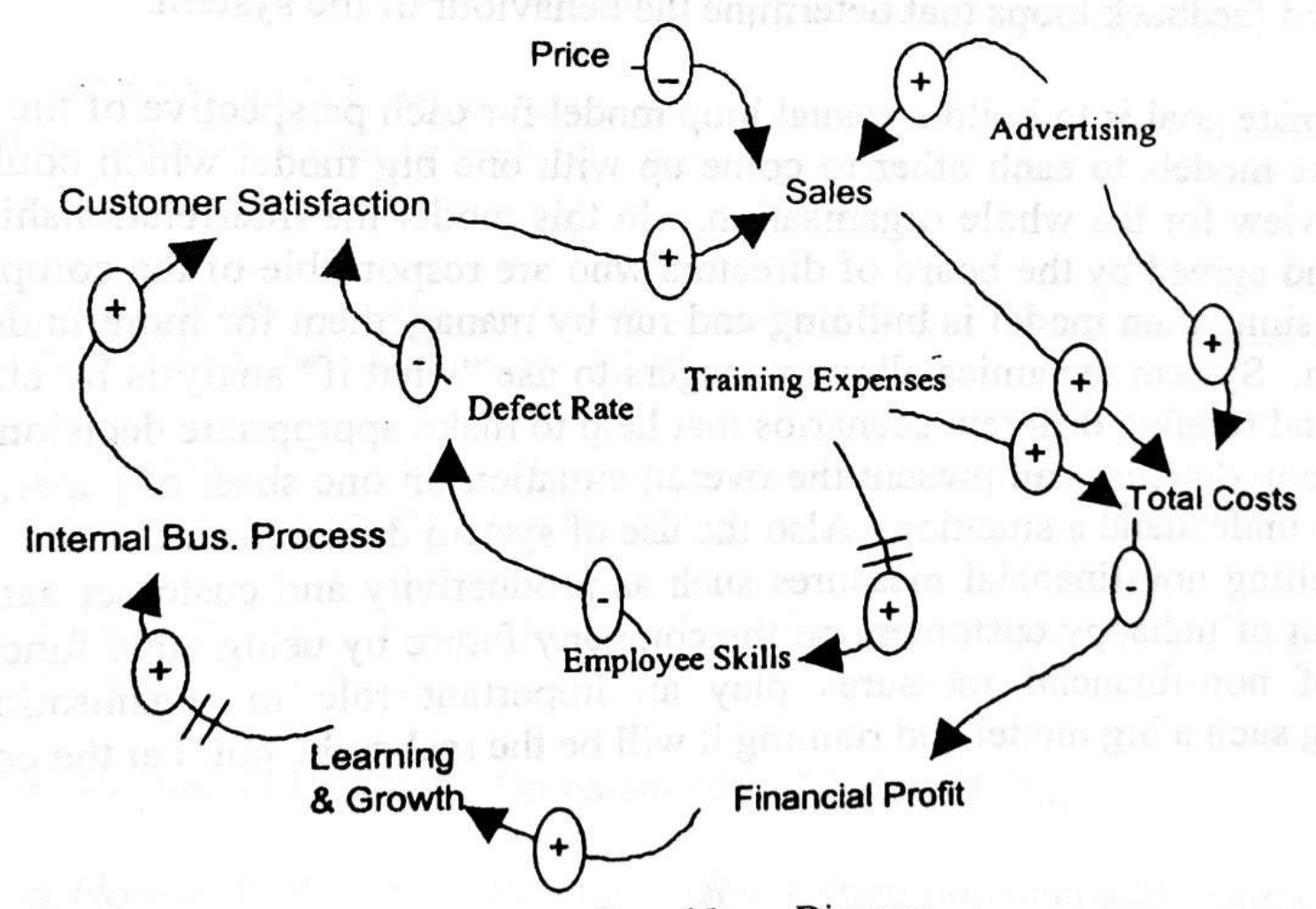

Figure two: Causal Loop Diagram

\section{Conclusion}

The Balanced Scorecard should be considered as a generic model. Thus, management could add one or more additional perspectives according to its aim. In some situations the supplies relationships are very important to the management as part of its strategy leading to breakthrough customer and financial performance. Then outcome and 
performance driver measures for supplier relationships should be incorporated within the firm's internal business process perspective. In other cases satisfying the external
environment (the community) is one of the main issues of the firms' strategy. Thus such perspective should be added to the company's' BSC then, objectives and measures for that perspective become an integral part of a company's BSC.

In this paper system dynamic approach is proposed as a tool to complement the BSC to overcome some of its limitations. It also can be used to solve difficult issues in developing strategies and performance measurement relying on the dynamical feedback that result from system dynamics models. The use of system dynamics enables management to be aware of a firm's situation inside and outside of the organisation. It is a tool that analyses and ensures that decisions are clearly linked to organisation objectives and goals. It gives mangers flexibility by introducing more than one scenario and gives the dynamics nature to the measurement system that would help the firm to be more lean and flexible.

All systems have some kind of delay, which can range from seconds to days or may be years. When the initial action is taken there is a response time until it starts to have impact on other components in the system. Using system dynamics as a supportive tool along with the BSC, the time lag problem previously mentioned in this paper can be solved by using the delay function. The use of system dynamics enables one to identify delays and feedback loops that determine the behaviour of the system.

The ultimate goal is to build a casual loop model for each perspective of the BSC. Then, link these models to each other to come up with one big model which could reflect the holistic view for the whole organisation. .In this model the interrelationships should be tested and agreed by the board of directors who are responsible of the company strategy. Then, a simulation model is building and run by management for more understanding of a system. System dynamics allow managers to use "what if" analysis by changing input values and running different scenarios that help to make appropriate decisions. The use of causal loop diagram can present the overall situation on one sheet of paper, which helps to better understand a situation. Also the use of system dynamics increases the flexibility in modelling non-financial measures such as productivity and customer satisfaction and the effect of unhappy customers on the company future by using table functions. These types of non-financial measures play an important role in organisational success. Building such a big model and running it will be the recherché point at the coming paper.

References

Banker et al, H. Chang and M. Pizzini., (2004). The balanced scorecard: Judgmental effects of performance measures linked to strategy, The Accounting Review 79 (2004) (1), pp. 1-23. 
Coyle, R.G., (1996). System dynamics modelling: A Practical Approach. Chapman\&
Hall, 2-6 Boundary Row, London SE Daupdinais W. and Price, C., 1998, Straight from the CEO, Nicolas Brearly, London. Forrester, Jay W., (1961). Industrial Dynamics. Portland, or: Productivity press, P. 14. Frederick Reichheld and W. Earl Sasser, Jr. "Zero Defection: Quality comes to Service
Harvard Business Review (September-October, 1990).

George W.L., Luiz and Richard L., Conceptual design of performance measurement anc management systems using structured engineering approach. International Journal of Productivity \& performance management, Vol. 54 No. 5/6, 2005, pp. 385-99.

Groesbeck, R.L., Sousa, G.W.L., Van Aken, E.M. and Coleman, G.D. (2002), "Using systems dynamics modelling to explore interrelationships in performance measurement scorecard", Proceedings of the 23rd American Society for Engineering Management National Conference, 2-5 October, Tampa, FL, pp. 255-63.

Ittner, D. Larcker and M. Meyer, Subjectivity and weighting of performance measures: evidence from a balanced scorecard, The accounting Review 78 (2003) (3), pp. 725-758

Ittner, D. Larcker and Randall, performance implications of strategic performance measurement in financial services firms, Accounting, Organizations and Society 28 (2003), pp. 715-741.

Ittner, D. Larcker, Coming up short on non-financial performance measurement, Harvarc Business Review (2003) (November), pp. 88-95.

Kaplan, R.S., \& Norton, D.P. (1992). The balanced Scorecard-Measures drive performance. Harvard Business Review, 70, 71-79.

Kaplan, R.S., \& Norton, D.P. (1996). Strategic learning and the balanced scorecard. Strategy and Leadership, 24, 18-25.

Kaplan, R.S., \& Norton, D.P. (2001). On balanced. CFO, 17, 73-78.

Kaplan, R.S., \& Norton, D.P. (2004). Strategy maps: Converting intangible assets to angible outcomes. Boston: Harvard Business School Press.

an Guo, Wei, and Dan Yang, Reducing conflict in balanced scorecard evaluations. The ccounting, Organization \& Society. 32, 4-5 May-July 2007, pp. 363-377.

awrie, G.J. and Cobbold, I. "Third-generation Balanced Scorecard: evolution of an ffective strategic control tool", International of Productivity and Performance Management,(2004). Vol. 53, No 7, pp. 611-23. 
Libby, Salterio and Webb, The balanced scorecard: the effects of assurance and process accountability on managerial judgment, the Accounting Review 79 (2004) (4), pp. 1075. ss
1094.

Lipe and Salterio,. The balanced scorecard: judgmental effects of common and unique performance measures, The accounting Review 75 (2000) (3), pp. 283-298.

Lipe and Salterio, . A note on the judgmental effects of the Balanced Scorecard's information organization, Account organ. Soc. 27 (2002), pp531-40.

Otley, D., (1999). Performance Management: A Framework for Management Control System Research. Management Accounting Research, Academic Press.

Roberts, M., Albright and A. Hibbets, Debasing balanced scorecard evaluations, Behavioral Research in Accounting 16 (2004), pp. 75-88

Santos, S.P., Belton, V. and Howick, S, "Adding value to performance measurement by using system dynamics and multi-criteria analysis", International Journal of Operation \&
Production Management, (2002), Vol. 22 No. 11, pp. 1246-72.

Senge, P.M. and Kleiner, A. et al. (1994), The Fifth Discipline Field book, Doubleday Sieger, Joseph M, "Manage Your Number to Match Your Strategy", Management Sterman, J.D. (2000), Business Dynamics-System Thinking and Modelling for a
Complex World, McGraw-Hill, New York, NY.

Wolstenholme, Eric (1998). Balanced Strategies for Balanced Scorecard: The Role of International System Dynamics Conference. 